\title{
Using cuticular wax alkanes to estimate herbage intake in animals fed supplements
}

\author{
H Dove 1, RW Mayes 2, M Freer 1 \\ 'CSIRO Division of Plant Industry, GPO Box 1600, Canberra, ACT 2601, Australia ; Macaulay \\ Land Use Research Institute, Craigiebuckler, Aberdeen AB9 2QJ, Scotland
}

The odd-chain hydrocarbons (alkanes) of plant cuticular wax, in combination with orally-dosed, even-chain alkanes of adjacent chain length, can be used to estimate herbage intake in ruminants (Mayes et al, 1986, J Agric Sci, Camb, 107, 161-170), provided the faecal recoveries of the two alkanes are similar. The method also can be applied to animals receiving supplements, provided the alkane content of the supplement and its intake by individual animals are known. However, there are no published data in which alkane-based estimates of herbage intake have been combined with independent estimates of supplement intake.

Individually-penned male castrate sheep ( $n=18$ ) were offered diets of lucerne chaff : oat grain in the ratios $593: 107,488: 214$ and $378: 322 \mathrm{~g} \mathrm{DM} / \mathrm{d}$ (6 sheep/diet). Intakes of the oat grain ('supplement') were estimated over a 6 -day period by labelling the grain with tritiated water (Juwarini et al, 1981, Aust J Exp Agric Anim Husb, 21, 395-399) and monitoring the accumulation of tritium in the body water pool, arising from the consumption of the labelled grain. The tritium content of the labelled oat grain and of body water (from jugular blood samples) was determined by liquid scintillation counting.

Over the same period, intakes of the chaff were estimated using the alkane method, by dosing the animals twice daily with capsules containing $40 \mathrm{mg}$ of each of C28 and C32 alkanes and taking rectal faeces samples. Alkanes were extracted from capsules and from freeze-dried herbage, grain and faeces samples and quantified by gas-liquid chromatography (Dove, 1992, Aust J Agric Res, 43, 1711-1724). Intakes of lucerne chaff were then calculated from the concentrations of adjacent odd-chain (natural) and even-chain (dosed, plus small quantities of natural) alkanes in the faeces and the diet components. Three estimates of lucerne intake were thus possible, based on the alkane pairs C28/C29, C31/C32 and C32/C33.

Supplement (oat grain) intakes estimated using tritium as a marker did not differ significantly from known supplement intakes. Intakes of lucerne chaff estimated using C28/C29 alkanes were significantly greater than the other estimates $(P<0.001)$ and overestimated known intakes by more than $21 \%$, partly because of a difference of $5 \%$ in the faecal recovery of these two alkanes. Intakes based on the C31/C32 pair over-estimated known intakes by $6 \%(P<0.05)$, but there was no significant difference between known intakes and those based on the $\mathrm{C} 32 / \mathrm{C}_{3} 3$ alkane pair, despite the relatively low content of $\mathrm{C} 33$ in lucerne. The results confirm earlier data based on known supplement intakes (Mayes et al, 1986), in demonstrating that dosed $\mathrm{C}_{32}$ and natural $\mathrm{C} 33$ alkanes can be used to obtain accurate estimates of herbage intake in animals which are also consuming grain supplements.

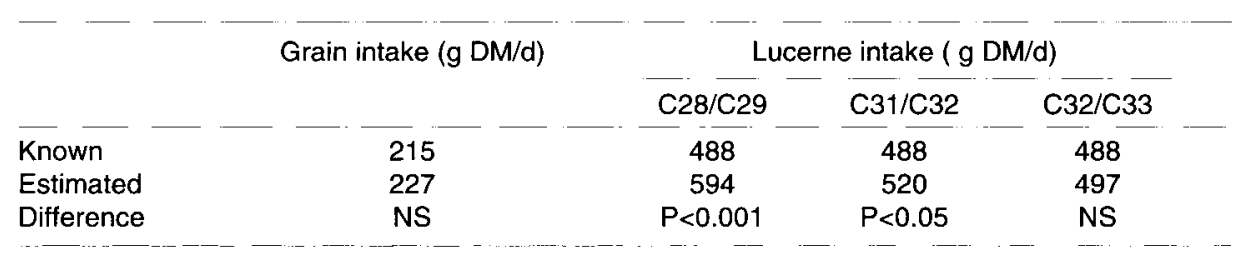

